\title{
COLOURFUL DIET FOR GOOD HEALTH
}

Vandana Gupta, Professor, Home-Science, Govt. MLB Girls P.G. College, Indore

Email: mailvandana@gmail.com

\section{ABSTRACT}

We are surrounded by colour and they can affect us profoundly and in ways that we may not have thought of. It is a known fact, that colours can influence your moods, feelings and emotions. Colours influence your actions and how you respond to people, situations and ideas. Apart from the colour of interiors, exteriors, our clothing and other things, the colour of food and beverage products are also extremely important. Green fruits and vegetables support eye health and may help protect against certain types of cancer. Orange and yellows fruits and vegetables are high in Vitamins $C$ and $B / f o l i a t e$ which may reduce risk of birth defects. Red fruits and vegetables protect the cells from free radical damage and healthy for the heart. Blue and purple fruits and vegetables may help reduce the risk of cancer, stroke, heart disease, memory decline and aging-related diseases. White fruits and vegetables may lower cholesterol and blood pressure as well as reduce risks of stomach cancer and heart disease. Therefore to keep ourselves in good health we should get a range of fruits and vegetables in varying hues over the course of a week.

\section{INTRODUCTION}

Our whole existence is covered with colours: the wonderful colours from nature, the colours of the objects in our home, the colours of our clothes, the colours of walls from the rooms, the colours of buildings, the colours of cars and different vehicles we are travelling by, the colours of books, magazines, papers, the colours from movie scenes and those seen on the TV, the coloured lights from the feast fireworks, the colours of Christmas decorations and gifts, or the colours of flowers we offer to our beloved ones for their anniversaries. All these represent as many moments we interfere with colours and get in contact with their effects. It is a known fact, that Colours can influence your moods, feelings and emotions. Colours influence your actions and how you respond to people, situations and ideas. Colours can affect us profoundly and in ways that you may not have thought of. Of course, we are surrounded by colour and normally take colours for granted.

\section{IMPORTANCE OF COLOURFUL FOOD}

Apart from the colour of interiors, exteriors, our clothing and other things, the colour of food and beverage products are also extremely important. "If food does not taste good, people will not try it again," says DDW Chairman and CEO, Ted Nixon. "If it doesn't look good, they may not try it at all."'

Food that looks good, tastes even better. When your kitchen, table or plate look dull and colourless, get creative with nature's rainbow. Prepare a colourful salad, create an arrangement of fruits. In some or the other way try to add colour to your plate. It looks beautiful, tastes great and yields many health benefits. Eating a rainbow of foods is a big plus on the healthy scale, Consuming different colour foods plays a role in insuring you are getting enough essential nutrients, vitamins, minerals, antioxidants, fiber, and more. Eating this way can help to protect against many potential body ailments and chronic diseases such as illnesses like the flu, cancers, digestive issues, declining vision, loss of bone density, and can even help with weight 


\section{INTERNATIONAL JOURNAL Of RESEARCH -GRANTHAALAYAH

management. Besides, your mood will most likely be lifted when your plate is full of a variety of visually appealing bright colours versus covered in a dull, white, and plain blandness.

\section{COLOUR WISE FOOD ITEMS AND THEIR BENEFITS}

GREEN FRUITS AND VEGETABLES

Green fruits and vegetables include: spinach, green beans, green cabbage, cucumbers, and other dark leafy greens and peas.

Health Benefits: Their colour comes from chlorophyll. Some dark greens are a good source of lutein works with zeaxanthin found in other coloured produce to support eye health while others contain indoles which may help protect against certain types of cancer. Chlorophyll colours nature green and is fundamental to superior physical and mental well being. Chlorophyll heals tissues in the body, counteracts inflammation, renews tissue growth and eliminates toxic waste debris from cellular metabolism.

Green apples contain a lot of fiber good for digestive and intestinal health, especially when eaten with the skin on. They are low in fat and help to regulate blood sugar, which is important for individuals with diabetes.

ORANGE AND YELLOWS FRUITS

Orange and yellows fruits and vegetables include: Mangoes, papaya, carrots, oranges, peaches, pumpkin, sweet corn.

Health Benefits: Their colour comes from carotenoids, which get converted by the body into Vitamin A -help protect against cancers, heart disease, age-related macular degeneration and other eye diseases. Citrus fruits in this category are high in Vitamins $\mathrm{C}$ and B/folate which may reduce risk of birth defects.

Whole or squeezed, lemons have incredible immune-boosting powers, and lemon juice is fantastic as a digestive aid and liver cleanser. Drinking warm lemon water each morning is a great way to wake up and to flush out toxins.

RED FRUITS AND VEGETABLES

Red fruits and vegetables includes: Apples, beets, red cabbage, cherries, red grapes, red peppers, radishes, strawberries, tomatoes, watermelon.

Health Benefits: Their red colour comes from lycopene which help reduce risk of cancer or anthrocynains a powerful antioxidants that protect the cells from free radical damage and healthy for the heart. Recent studies using purified anthocyanins or anthocyanin-rich extracts on in vitro experimental systems have confirmed the potential potency of these pigments. Demonstrable benefits include protection against liver injuries; significant reduction of blood pressure; improvement of eyesight; strong anti-inflammatory and antimicrobial activities. .

Red colour tomatoes contain lycopene, a red pigment that may help with protecting against breast and prostate cancers. Tomatoes are also loaded with antioxidants from vitamins $\mathrm{A}$ and $\mathrm{C}$ to help protect against cell damage. Leave those tomato skins on and eat raw.

BLUE AND PURPLE FRUITS AND VEGETABLES

Blue and purple fruits and vegetables includes: Blueberries, Brinjal, figs, plums, purple grapes and raisins.

Health Benefits: Their dark colour comes from anthocyanains a powerful antioxidant that may help reduce the risk of cancer, stroke, heart disease, memory decline and aging-related diseases. 


\section{INTERNATIONAL JOURNAL Of RESEARCH -GRANTHAALAYAH

Art

\section{WHITE FRUITS AND VEGETABLES}

White fruits and vegetables include: Bananas, cauliflower, garlic, mushrooms, onions, potatoes, Radish and turnips.

Health Benefits: Their white colour comes from anthoxanthins. Foods in this category may contain allicin which may lower cholesterol and blood pressure as well as reduce risks of stomach cancer and heart disease. Some "white" foods may also provide us with the mineral, potassium.

Garlic is not only extremely healthy and tastes fabulous in cooking, but it also acts as a natural health remedy for various ailments, strengthening the immune system and is used in fighting off infections, congestion, and the flu. Garlic is an excellent source of vitamin B6, which is needed to keep a healthy immune system and for new cell growth.

More and more experts are saying healthy eating is not only about how many servings you eat. It's about the variety you pick, too. Differently coloured fruit and vegetables often contain different nutrients so it's a good idea to eat a wide range of colours . One study found that people who eat the widest range of fruit and vegetables have $22 \%$ lower risk of mouth cancer than those who eat the narrowest range (Garavello 2008).

If you eat a diet of solely white foods, you'll miss key nutrients your body needs-even if your palette includes cauliflower, onions, and mushrooms. Adding a multivitamin doesn't cut it either. "People will say, 'I'm taking a multivitamin, so I don't really need to eat these,' " says Karin Hosenfeld, RD, LD, a dietician in private practice in Dallas, but she says scientists don't know whether whole foods may offer undiscovered benefits that vitamins don't. "We do know for sure that if you don't eat your fruits and vegetables, you're not getting your fiber, and that's help in keep your blood sugar down."

Every one of your meals doesn't have to be multicoloured though it wouldn't hurt to add a salad with different-coloured veggies to the menu, but you should get a range of fruits and vegetables in varying hues over the course of a week. "We know that the most vibrantly coloured fruits and vegetables have the most nutrition," says Hosenfeld. "Eating an array of colours just ensures that you get the benefits of all of them."

\section{REFERENCES}

1 Schaeffe, J.: Color Me Healthy - Eating for a Rainbow of Benefits, Today's Dietitian, Vol. 10, No. 11, P. 34, November 2008.

2 Konczak, I. and Zhang, W.: Anthocyanins-More Than Nature's Colours, Journal of Biomedicine and Biotechnology, Vol. 5, p. 239-40, Dec. 2004.

3 Graci, S.: Nature Colours Itself Green, Whole Earth and Sea, Nov.2014

4 IARC, World Cancer Report, ed. B. Stewart and P. Kleihues. Lyon. IARC Press, 2003,

5 Garavello, W. etal:. Diet diversity and the risk of oral and pharyngeal cancer. Eur $J$ Nutr, 2008.

6 Alizon, "Colours - Colour Meaning for Magic, Healing and Enhancing you Life", Available at http://www.alizons-psychic-secrets.com/colours.html, site accessed on 7th November 2014.

7 Nixon, Ted, in "Why Colour?", Available at http://www.ddwcolor.com/hue/why-color/, site accessed on 7th November 2014. 